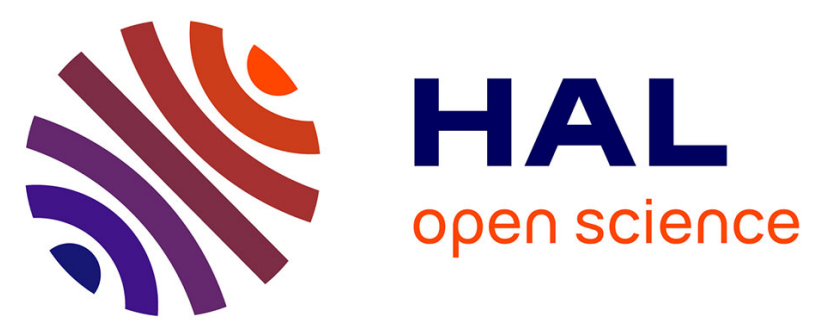

\title{
RAS mutation testing in patients with metastatic colorectal cancer in French clinical practice: A status report in 2014
}

Astrid Lièvre, Jean-Louis Merlin, Jean-Christophe Sabourin, Pascal Artru, Sabine Tong, Lucie Libert, François Audhuy, Corinne Gicquel, Laurence Moureau-Zabotto, Roch-Anicet Ossendza, et al.

\section{To cite this version:}

Astrid Lièvre, Jean-Louis Merlin, Jean-Christophe Sabourin, Pascal Artru, Sabine Tong, et al.. RAS mutation testing in patients with metastatic colorectal cancer in French clinical practice: A status report in 2014. Digestive and Liver Disease, 2018, 50 (5), pp.507-512. 10.1016/j.dld.2017.12.029 . hal-01778377

\section{HAL Id: hal-01778377}

https://hal-univ-rennes1.archives-ouvertes.fr/hal-01778377

Submitted on 23 Aug 2018

HAL is a multi-disciplinary open access archive for the deposit and dissemination of scientific research documents, whether they are published or not. The documents may come from teaching and research institutions in France or abroad, or from public or private research centers.
L'archive ouverte pluridisciplinaire HAL, est destinée au dépôt et à la diffusion de documents scientifiques de niveau recherche, publiés ou non, émanant des établissements d'enseignement et de recherche français ou étrangers, des laboratoires publics ou privés. 


\section{RAS mutation testing in patients with metastatic colorectal cancer in French clinical}

practice: a status report in 2014 (119/160 characters)

Astrid Lièvre ${ }^{\mathrm{a}, \mathrm{b}, \mathrm{c}, *}$, M.D., Ph.D., Jean-Louis Merlin ${ }^{\mathrm{d}, \mathrm{e}, \mathrm{f}}$, Pharm.D., Ph.D., Jean-Christophe Sabouring,h, M.D., Pascal Artru' ${ }^{i}$ M.D., Sabine Tongj, MSc, Lucie Libert', MSc, François Audhuy $^{\mathrm{k}}$, MSc, Corinne Gicquel ${ }^{\mathrm{k}}$, MSc, Laurence Moureau-Zabottol, M.D., Roch-Anicet Ossendza $^{\mathrm{m}}$, M.D., Pierre Laurent-Puign,o, M.D., Michel Ducreux ${ }^{\mathrm{p}}$, M.D.

a Service des Maladies de l'appareil digestif, CHU Pontchaillou, 2 Rue Henri le Guilloux, 35000 Rennes

b Université Rennes 1, Faculté de Médecine, 2 Avenue du Professeur Léon Bernard, 35000 Rennes, France

c INSERM U1242, COSS (Chimie, Oncogenèse, Stress et Signalisation), Rue de la Bataille Flandres Dunkerque, 35000 Rennes, France

d Université de Lorraine, 34 Cours Léopold, 54000 Nancy, France

e CNRS UMR7039 CRAN, Boulevard des Aiguillettes, 54506 Vandoeuvre-lès-Nancy, France

${ }^{\text {f }}$ Service de Biopathologie, Institut de Cancérologie de Lorraine, 6 Avenue de Bourgogne, 54519 Vandoeuvre-lès-Nancy, France

g Service d'Anatomie et de Cytologie Pathologiques, CHU Charles Nicolle, 1 Rue de Germont, 76000 Rouen, France

h Inserm 1079, Université de Normandie, 22 Boulevard Gambetta, 76183 Rouen, France

i Service d'Oncologie digestive, Hôpital Jean Mermoz, 55 Avenue Jean Mermoz, 69008 Lyon, France

j Axonal, 215 Avenue Georges Clemenceau, 92000 Nanterre, France

k Merck Santé, 37 Rue Saint-Romain, 69008 Lyon, France 
${ }^{\text {l }}$ Service de Radiothérapie, Institut Paoli-Calmettes, 232 Boulevard Sainte Marguerite, 13273 Marseille, France

m Service d'Hépato-Gastro-Entérologie, Centre Hospitalier Chalons-en-Champagne, 51 Rue du Commandant Derrien, 51005 Chalons-en-Champagne, France

n UMRS-1174 Médecine Personnalisée, Pharmacogénomique, Optimisation Thérapeutique, Université Paris Descartes, 12 Rue de l'Ecole de Médecine, 75006 Paris, France

o Service de Biologie, Hôpital Européen Georges Pompidou, 20 Rue Leblanc, 75015 Paris, France

p Département de Médecine Oncologique, Gustave Roussy, 114 Rue Edouard Vaillant, 94800 Villejuif, Université Paris-Saclay, France

* Corresponding author: Pr Astrid Lièvre, Service Maladies de l'appareil digestif, CHU Pontchaillou, 2 Rue Henri le Guilloux, 35000 Rennes, Tel.: +33 (0)299289972; Fax: +33 (0)299284189; e-mail: astrid.lievre@chu-rennes.fr

Proofs should be sent to: Pr Astrid Lièvre, Service Maladies de l'appareil digestif, CHU Pontchaillou, 2 Rue Henri le Guilloux, 35000 Rennes. e-mail: astrid.lievre@chu-rennes.fr

\footnotetext{
Abstract (194/200 words)

Background: RAS (NRAS+KRAS) mutation testing is required in addition to simple KRAS testing prior to initiating anti-epidermal-growth-factor-receptor (EGFR) antibodies (MAb) as in metastatic colorectal cancer (mCRC).

Aims: To assess prescription and implementation rates of $R A S / K R A S$ mutation testing. To describe the RAS/KRAS mutation test procedure and its impact on therapeutic strategy.
} 
Patients and Methods: Observational retrospective study conducted from June to September 2014 in all consecutive patients with newly diagnosed mCRC.

Results: Data from 375 patients (male: 57.8\%; mean age, 65.7 \pm 11.7 years) were analysed. RAS/KRAS mutation testing was prescribed in $90.1 \%$ of patients (338/375). The test was prescribed within 1 month around mCRC diagnosis and prior to first-line therapy in $73.1 \%$ (242/331) and 85.4\% (280/328) of patients, respectively. Time from test request to receipt of results was $24.6 \pm 17.2$ days. $59.7 \%$ of patients (190/318) had a mutation, mainly KRAS (47.9\%; 152/317). Anti-EGFR MAb was prescribed in 90.9\% of RAS-wild-type cases (60/66), consistent with the goal of genotyping-testing in this population.

Conclusion: In 2014, RAS genotyping-testing in addition to KRAS testing was routinely prescribed and performed in mCRC patients in France. Time to receive results remains long and must be reduced so as to match clinical practice.

Key words: RAS; KRAS mutations; genotyping; colorectal cancer (4/4 key words) 


\section{Introduction}

Colorectal cancer (CRC) is the second most common cause of cancer death in Europe, with 446,800 new CRC diagnoses and 214,700 disease-related deaths in 2012 [1]. Approximately $20 \%$ of the patients have metastatic disease at initial diagnosis, and an additional $30 \%$ to $40 \%$ develop metastases during the course of the disease [2]. Twenty years ago, patients with metastatic colorectal cancer (mCRC) had a 5-year survival rate of only $11 \%$ [2]. Progress has been made through improvements in treatment, including targeted therapies. Anti-epidermal growth factor receptor monoclonal antibodies (anti-EGFR MAb) such as cetuximab and panitumumab have emerged as effective in a subset of mCRC patients and were initially approved in refractory mCRC, but then reported to be ineffective in tumours with mutations in codons 12 and 13 of exon 2 of the KRAS gene [3, 4]. In addition to the KRAS exon 2 mutation, in 2013 it was shown that mutations in KRAS exons 3 and 4, and in NRAS exons 2 to 4 had similar negative impact on anti-EGFR MAb efficacy [5], and anti-EGFR MAbs were therefore restricted to mCRC patients without so-called "RAS mutations" (KRAS or NRAS mutations), improving target population definition.

In 2011, we conducted the French national Flash-KRAS study, showing that KRAS testing (exon 2 exclusively) was well-established in the management of mCRC patients in clinical practice in France, despite some regional discrepancies [6]. In 2014, we conducted the present Flash-RAS observational study to assess whether the genotyping tests were performed in accordance with the intervening changes in approved indications for anti-EGFR MAbs. The primary objective was to evaluate the prescription and implementation rates of $R A S$ mutation testing in newly diagnosed mCRC patients (approved indication). Secondary objectives comprised analysis of reasons for non-prescription of testing, timing of the RAS testing 
process from prescription to results, techniques used to determine $R A S$ status, and impact of RAS status on treatment strategy.

\section{Patients \& Methods}

Patient selection

This national multicentre non-interventional retrospective study was conducted with oncologists, gastroenterologists, and radiotherapists treating patients with mCRC in mainland France. Participating physicians were to screen consecutive patients seen in daily practice satisfying the following criteria: age $\geq 18$ years, with mCRC confirmed histologically after March 2014 (date at which the NRAS tests became available in France), seen in consultation between June 15th, 2014 and September 30th, 2014, and initiating or having initiated first-line therapy for mCRC during that period. The study complied with the principles of the Declaration of Helsinki and the international directives (ICH3) for non-interventional studies. All participants gave oral consent prior to inclusion.

Data collection

Data were collected from patients' medical files and recorded in a questionnaire collecting patient and tumour characteristics, first-line chemotherapy, details of the RAS/KRAS mutation test process (i.e., NRAS+KRAS or KRAS exons 2, 3 and 4, sometimes in association with $B R A F$ ) from test request to reception of results, reason(s) for request or non-request for mutation testing, and impact of results on therapeutic management. When available, an anonymized copy of the genotyping test report was added to the questionnaire. 


\section{Statistical Analysis}

Patients' demographic and disease characteristics and treatments were reported as standard statistics: mean and standard deviation (SD), median, range, interquartile range for quantitative parameters, and number and percentage for qualitative parameters (excluding missing data). Statistical analysis used SAS ${ }^{\circledR}$ software, version 9.2, (SAS Institute Inc., Cary, NC, USA). The number and percentage of requests for RAS mutation testing were reported with their 95\% confidence interval (95\%CI). Analysable patients were all patients enrolled in the study and respecting selection criteria.

\section{Results}

Centres, patients and disease characteristics

2,700 oncologists, gastroenterologists, and radiotherapists, representative of the nationwide population of physicians treating CRC, were invited to participate in the study: 298 accepted, and 104 finally enrolled a total of 406 patients (median: 3 patients per physician). Mean age of physicians was $44.5 \pm 7.1$ years; the majority were male (61.2\%), and most were practicing in private clinics/hospitals (41.2\%), or general hospitals (30.6\%).

Data for 375 of the 406 enrolled patients were analysed (Table 1). The most commonly used first-line chemotherapies were FOLFOX and/or XELOX (51.1\%; 186/364) and FOLFIRI and/or IRINOTECAN (32.1\%; 117/364). More than half of the patients (53.2\%; 198/372) received targeted therapy. Desired location of Table 1 
$R A S / K R A S$ mutation test requests

RAS/KRAS mutation testing was requested for $90.1 \%$ of patients (338/375) and a report of the results was available for $84.8 \%$ of patients (318/375) (Figure 1). Reasons for non-request were provided for 28 patients (9 missing data). The main reason for non-request was that no anti-EGFR MAb therapy was planned by the physician (57.1\%; 16/28); other reasons included the patient's age or general condition $(10.7 \%$; 3/28), scheduled metastasis resection surgery (10.7\%; 3/28), excessive delay in obtaining test results (5.4\%; 2/28), multidisciplinary team decision (7.1\%; 2/28), and “other" (7.1\%; 2/28). Desired location of Figure 1 RAS/KRAS mutation testing was mainly requested by oncologists $(50.4 \%$; $169 / 335)$ and gastroenterologists (24.2\%; 81/335). In most cases (86.4\%; 286/331), physicians requested testing of both NRAS and KRAS (BRAF testing being sometimes requested in association with NRAS/KRAS). Simple KRAS mutation testing was requested for $9.2 \%$ of patients for whom a test was requested (31/338) (Table 2). The most frequently used technique of enrichment of mutated RAS gene alleles was pyrosequencing/sequencing/snapshot (59.8\%; 202/338).

Most patients (73.1\%; 242/331) had a RAS/KRAS test request within 1 month around the diagnosis of metastatic disease. For $22.1 \%$ of patients (73/331), the test was requested more than 1 month after this diagnosis. It was requested before initiation of first-line therapy for $85.4 \%$ of patients for whom a test was requested and data were available (280/328) (Table 2).

\section{Desired location of Table 2}

The oncogenetics platform was located outside the mCRC treatment centre for $80.7 \%$ of patients for whom a test was requested and data were available (268/332). The mean time between request for $R A S / K R A S$ mutation testing and receipt of the results report was $24.6 \pm$ 17.2 days (median: 20 days). The duration of the overall process is detailed in Table 3. The median time for biomarker genotyping varied slightly according to analytic technique: 13 
days for pyrosequencing and allelic discrimination, 10 days for high resolution melting, and 12 days for other techniques. No patient-, tumour- or practitioner-related factors were significantly associated with time to obtain results. Desired location of Table 3

Mutation test results

$59.7 \%$ of patients with available $R A S( \pm B R A F)$ mutation results (190/318) had 1 mutation. KRAS mutations were identified in $47.9 \%$ of patients (152/317), NRAS mutations in $8.7 \%$ (20/231) and BRAF mutations in 10.0\% (25/250). For 59.6\% of patients (180/302), all 6 exons (KRAS exons 2, 3, 4 plus NRAS exons 2, 3, 4) were analysed. There were 44 patients with full $R A S$ genotyping request for whom only KRAS exon 2 was in fact tested; in 41 of these cases, exon 2 was mutated, and this finding likely stopped the genotyping sequence.

Impact of $R A S$ mutations on therapeutic management

According to the physicians, RAS mutation status had an impact on the therapeutic management of 94 of the 179 patients (52.5\%) with 1 RAS mutation, and of 71 of the 120 (59.2\%) with wild-type RAS. Treatment changes, known for 76 of the 94 RAS-mutated patients, were, in decreasing order: anti-VEGF MAb initiation (bevacizumab: 39.5\%; 30/76), no anti-EGFR MAb prescription despite being initially considered (22.4\%; 17/76), and chemotherapy regimen change (17.1\%; 13/76). Changes, known for 66 of the 71 wild-type RAS patients, were mainly anti-EGFR MAb (cetuximab, panitumumab) initiation (90.9\%; 60/66 patients) (Figure 2). An anti-EGFR MAb (cetuximab, panitumumab) was prescribed for 10 of the 179 patients (5.6\%) with a RAS mutation, despite the change in marketing authorizations. Desired location of Figure 2 


\section{Discussion}

This study was the first to describe the prevalence and procedure of RAS (KRAS+NRAS) mutation testing in routine practice at national level in France, since the approved indication for anti-EGFR MAbs in patients without activating RAS mutations.

The study showed that $R A S$ mutation testing was routinely performed as part of mCRC patient management in 2014 in France. Compared to 2011, the rate of genotyping testing requests increased from $81.1 \%$ in the 2011 Flash-KRAS study [6] to $90.1 \%$ in the present study, indicating clinical integration of anti-EGFR MAbs guidelines. For $9.2 \%$ of patients, mutation testing was requested for KRAS only, possibly because the study was conducted shortly after these recommendations were added to the cetuximab and panitumumab summaries of product characteristics $[7,8]$.

In 2014, as previously observed in the 2011 Flash-KRAS study [6], the test was prescribed early during mCRC patient management: within 1 month around the diagnosis of metastases in $73.1 \%$ of patients, and before initiation of first-line therapy in $85.4 \%$. However, for $22.1 \%$ of the patients, the test was requested more than 1 month after diagnosis and, for $14.6 \%$, after initiation of first-line therapy, which is not compatible with an informed choice of first-line treatment according to the patient's RAS status.

A mutation was identified in $59.7 \%$ of the patients, and mainly consisted in KRAS mutation. In more than half of the patients, all 6 exons were analysed (KRAS exons 2, 3, and 4 plus NRAS exons 2, 3, and 4). Genotyping was in some cases conducted sequentially, and in 44 patients only KRAS exon 2 was analysed despite a request for full RAS genotyping, almost always because of early discovery of a KRAS exon 2 mutation. 
Regarding time to obtain results, the mean time for the whole test procedure (from test request to the results feedback) was $24.6 \pm 17.2$ days (median: 20 days) in 2014, similar to that reported in the 2011 Flash-KRAS study (23.6 \pm 28.2 days; median: 19 days). The narrower standard deviation, however, indicates a trend for more uniform feedback times in 2014, suggesting greater uniformity and coordination of mCRC patient management in the deployment of these new tests. This time interval was slightly shorter than reported in a previous French retrospective study [9] but remains long and hardly acceptable in clinical practice. The interval exceeded the maximum 10 working days recommended by European EQA schemes in 2013 [10], the 7-to-10 working days recommended by the French National Cancer Institute (INCa) in 2010 [11], and the median 9 days (range: 4-21 days) specified in the summary of the activity of the French hospital molecular genetics platforms in 2012 [12]. In a large study (2,510 tumour samples) performed in Germany from 2014 to 2016, 72\% of RAS results were reported within 6 working days (lab turnaround time) [13]. In Canada, median turnaround time for EGFR results in lung cancer was 18 days (range: 15-26 days) in one study [14], and 21 days in another in which EGFR and $A L K$ mutation tests were performed after the first oncology consultation [15]. In the present study, time from dispatch to the technical platform to reception of the report was longer in 2014 (19.5 \pm 15.8 days; median: 15 days) than 2011 (mean $14.0 \pm 11.0$ days; median: 11 days), probably due to the greater number of exons tested (1 in 2011 versus 6 in 2014).

The combination of pyrosequencing/sequencing/snapshot was the most frequent technique used for analysis of mutations, whatever the allele studied (KRAS, NRAS, or BRAF). This technique tended to replace sequencing by Sanger's method, previously considered as the "gold standard'. According to the literature, between 7\% and 20\% of CRC cases characterised as wild-type by Sanger sequencing or real-time PCR were found to harbour KRAS codon 12 
or 13 mutations on pyrosequencing, locked nucleic acid PCR or mutant-enriched PCR techniques [16-19].

With regard to the impact on therapeutic management, the results of $R A S / K R A S$ mutation testing showed that, when absence of mutation was confirmed, a majority of patients (90.9\%: 60/66) were prescribed an anti-EGFR MAb, consistent with the goal of genotyping testing in this population. For a limited number of patients with a RAS mutation (5.6\%: 10/179), an antiEGFR MAb (cetuximab, panitumumab) was prescribed, despite the restriction laid down in the market approval, which may suggest that there is still room for improvement in therapeutic practices.

This study has some limitations owing to its observational nature, and possible selection bias for the physicians and patients participating. Only 104 of the 2,700 physicians contacted included at least 1 patient. Difficulties of recruitment led to a small number of included patients, which may limit extrapolation to a wider patient population. However, patient characteristics and distributions by centres and regions were representative of the population of mCRC patients, although 4 of the 22 French administrative Regions were overrepresented and 3 were not represented [20]. Missing data, especially concerning time between $R A S / K R A S$ mutation test request and reception of the genotyping report, constituted another limitation.

Liquid biopsy, analysing circulating tumour DNA (ctDNA), has emerged as new non-invasive procedure for detecting gene mutations in cancer patients. In a recent study, this method detected ctDNA in 100\% of patients and exhibited high specificity (98\%) and sensitivity (92\%) for 7 KRAS point mutations [21]. While liquid biopsy is not yet well established in routine clinical practice, it could advantageously replace tumour section analysis for detection of RAS mutations, reducing procedure time. Liquid biopsy could bypass the time-consuming and therefore limiting steps of unarchiving, selecting and dispatching samples to the 
oncogenetics platform. This method may, therefore, expand the scope of personalized medicine for cancer patients.

In conclusion, this study showed that, in 2014, RAS mutation genotyping testing was a routine part of mCRC patient management in France. Compared to 2011, the rate of genotyping testing requests increased markedly. Overall, mCRC patient management was consistent with health authority guidelines, according to RAS status. However, the interval between test request and results feedback was longer than expected, and is not acceptable in clinical practice; this delay must be reduced. Standardization of assessment methods at European level could be a way to shorten this delay.

\section{Funding}

This study was sponsored by Merck Santé SAS, Lyon, France, an affiliate of Merck KGaA, Darmstadt, Germany. The management of the study was provided by Merck Santé. The management, monitoring, data management and the statistical analyses were performed by, AXONAL-BIOSTATEM, Nanterre, France. The sponsor participated in the design of the study, had oversight on the conduct of the study, and participated in interpretation of data and the decision to publish the results. The corresponding author had full access to all of the data and the final responsibility to submit for publication.

\section{Authors' disclosures of potential conflicts of interest:}

AL: Merck, Baxalta, Ipsen (board member), Merck, Amgen, Roche, Lilly, Novartis (lecturer). JLM: Merck, Amgen (board member and lecturer), Sanofi (lecturer)

JCS: Merck, Amgen, MSD, BMS, Roche, Astra Zeneca, Pfizer, Boehringer Ingelheim (board member) 
PA: Roche, Merck (board member) Sanofi, Amgen, Lilly (lecturer)

ST and LL worked for Axonal, which received funding from Merck, at the time of the study. FA and CG worked for Merck at the time of the study

LMZ: None

RAO: None

PLP: Merck, Boehringer-Ingelheim, Pfizer, Astra Zeneca, Biocartis (board member), Lilly, Sanofi, Roche, Astra-Zeneca (lecturer)

MD: Roche, Merck Serono, Amgen, Lilly, Sanofi, Novartis, Servier, Ipsen (board member and lecturer), Sanofi (grant)

\section{Acknowledgments}

We would like to thank Merck Santé SAS, Lyon, France, an affiliate of Merck KGaA, Darmstadt, Germany, for funding, David Tougeron, Romain Coriat, Stefano Kim and Karima Yakendji Bekredda for their involvement in the study, ICTA PM for editorial support, Abelia Science for the assistance provided in preparing this article, and Iain McGill for revision of the English text. 


\section{References}

1. Ferlay J, Steliarova-Foucher E, Lortet-Tieulent J, et al. Cancer incidence and mortality patterns in Europe: estimates for 40 countries in 2012. Eur J Cancer 2013;49(6):1374403.

2. Kjeldsen BJ, Kronborg O, Fenger C, et al. The pattern of recurrent colorectal cancer in a prospective randomised study and the characteristics of diagnostic tests. Int J Colorectal Dis 1997;12(6):329-34.

3. Bokemeyer C, Bondarenko I, Hartmann JT, et al. Efficacy according to biomarker status of cetuximab plus FOLFOX-4 as first-line treatment for metastatic colorectal cancer: the OPUS study. Ann Oncol 2011;22(7):1535-46.

4. Van Cutsem E, Kohne CH, Hitre E, et al. Cetuximab and chemotherapy as initial treatment for metastatic colorectal cancer. N Engl J Med 2009;360(14):1408-17.

5. Douillard JY, Oliner KS, Siena S, et al. Panitumumab-FOLFOX4 treatment and RAS mutations in colorectal cancer. N Engl J Med 2013;369(11):1023-34.

6. Lievre A, Artru P, Guiu M, et al. The KRAS mutation detection within the initial management of patients with metastatic colorectal cancer: a status report in France in 2011. Eur J Cancer 2013;49(9):2126-33.

7. Summary of Product Characteristics. Erbitux ${ }^{\circledR}$ (cetuximab), last updated 27 January 2014.

8. Summary of Product Characteristics. Vectibix ${ }^{\circledR}$ (panitumumab), last updated 26 May 2015.

9. Bibeau F, Louvet C, Afchain P, et al. [Observational study on conditions for access to the analysis of KRAS mutation in patients with metastatic colorectal cancer receiving panitumumab treatment]. Bull Cancer 2012;99(7-8):743-51. 
10. van Krieken JH, Siebers AG, Normanno N. European consensus conference for external quality assessment in molecular pathology. Ann Oncol 2013;24(8):1958-63.

11. INCa, editor. Bonnes pratiques pour la recherché à visée théranostique de mutations somatiques dans les tumeurs solides. Collection Outils pour la pratique des autres professionnels de santé / Anatomopathologie. Boulogne-Billancourt; 2010 [In French]. Available at: www.ecancer.fr/content/download/63175/568709/file/OUTTHERANOS10.pdf

12. INCa, editor. Synthèse de l'activité des plateformes hospitalières de génétique moléculaire des cancers en 2012, en vue d'optimiser leur evolution. Collection Bilans d'activité et d'évaluation. Boulogne-Billancourt; 2014 [In French]. Available at http://www.e-cancer.fr/content/download/63494/571261/file/Synthese-activiteplateformes-hospitalieres-genetique-moleculaire-en-2012-2014.pdf

13. Schirmacher P, Tannapfel A, Dietel M, et al. RAS Registry: Molecular pathological analysis of RAS mutations in mCRC. Virchows Arch 2017;471(Suppl 1):S33-4.

14. Ellis PM, Verma S, Sehdev S, et al. Challenges to implementation of an epidermal growth factor receptor testing strategy for non-small-cell lung cancer in a publicly funded health care system. J Thorac Oncol 2013;8(9):1136-41

15. Lim C, Tsao MS, Le LW, et al. Biomarker testing and time to treatment decision in patients with advanced nonsmall-cell lung cancer. Ann Oncol 2015;26(7):1415-21.

16. Bando H, Yoshino T, Tsuchihara K, et al. KRAS mutations detected by the amplification refractory mutation system-Scorpion assays strongly correlate with therapeutic effect of cetuximab. Br J Cancer 2011;105(3):403-6.

17. Molinari F, Felicioni L, Buscarino M, et al. Increased detection sensitivity for KRAS mutations enhances the prediction of anti-EGFR monoclonal antibody resistance in metastatic colorectal cancer. Clin Cancer Res 2011;17(14):4901-14. 
18. Dono M, Massucco C, Chiara S, et al. Low percentage of KRAS mutations revealed by locked nucleic acid polymerase chain reaction: implications for treatment of metastatic colorectal cancer. Mol Med 2012;18:1519-26.

19. Tougeron D, Lecomte T, Pages JC, et al. Effect of low-frequency KRAS mutations on the response to anti-EGFR therapy in metastatic colorectal cancer. Ann Oncol 2013;24(5):1267-73.

20. Merlin J-L, Lièvre A, Laurent-Puig $\mathrm{P}$, et al. [A retrospective observational study on KRAS and NRAS testing in 2014 in patients with metastatic colorectal cancer (mCRC).]. In: Seventh French Symposium of Pharmaco-Epidemiology (PEP); 2015; Paris, France; 2015.

21. Thierry AR, Mouliere F, El Messaoudi S, et al. Clinical validation of the detection of KRAS and BRAF mutations from circulating tumor DNA. Nat Med 2014;20(4):430-5. 
Figure 1: Study flowchart

${ }^{a}$ A given patient might show several major protocol deviations: diagnosis of mCRC before $2014(\mathrm{~N}=11)$; refusal of data collection $(\mathrm{N}=10)$; no informed consent $(\mathrm{N}=4)$; $>1$ prior line of mCRC therapy $(\mathrm{N}=10)$; and/or participation in a concomitant interventional study $(\mathrm{N}=12)$.

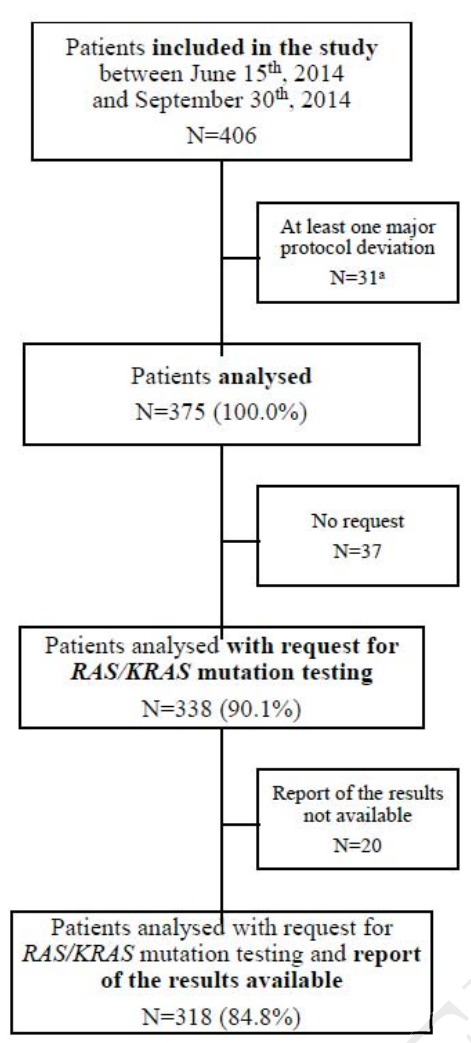


Figure 2: Impact of RAS mutations on therapeutic management

a318 of the 338 patients with at least 1 RAS/KRAS mutation test request (94.1\%) had results available for RAS mutations.

RAS: KRAS+NRAS or KRAS+NRAS+BRAF

EGFR: epidermal growth-factor receptor; MAb: monoclonal antibody; VEGF: vascular endothelial growth factor

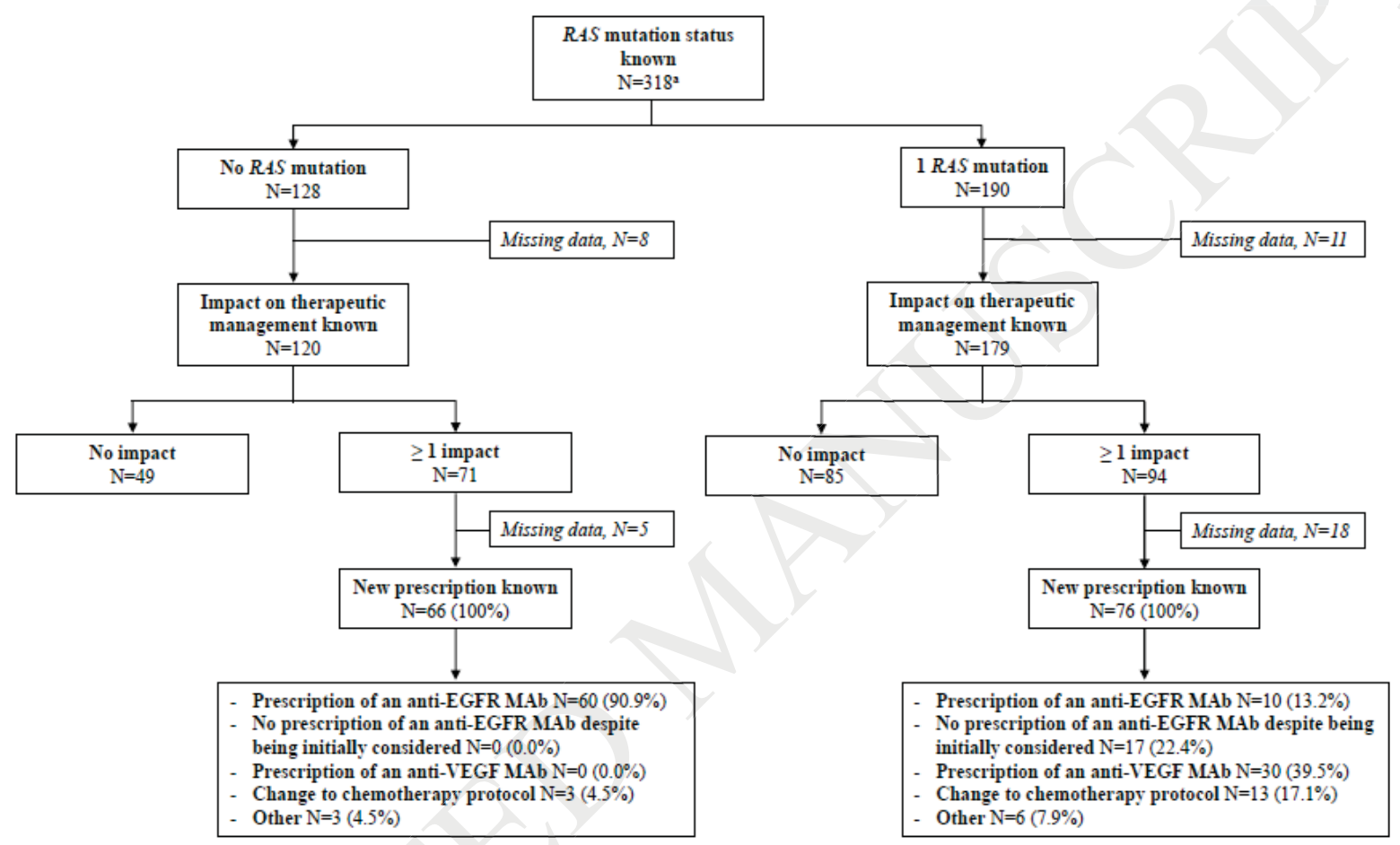


Table 1: Patient and tumour characteristics

\begin{tabular}{|c|c|}
\hline & $\begin{array}{c}\text { Total } \\
(\mathrm{N}=375)\end{array}$ \\
\hline Gender, n (\%) & $\mathrm{N}=374$ \\
\hline Male & $216(57.8 \%)$ \\
\hline Age in years & $\mathbf{N}=371$ \\
\hline Mean \pm SD & $65.7 \pm 11.7$ \\
\hline Median & 67 \\
\hline Q1-Q3 & $58-74$ \\
\hline Location of primary tumour, $\mathrm{n}(\%)$ & $\mathrm{N}=370$ \\
\hline Colon & $282(76.2 \%)$ \\
\hline Rectum & $86(23.2 \%)$ \\
\hline Colon + Rectum & $2(0.5 \%)$ \\
\hline TNM Stage at the time of the CRC diagnosis, n (\%) & $\mathrm{N}=367$ \\
\hline I-II & $38(10.4 \%)$ \\
\hline III & $59(16.1 \%)$ \\
\hline IV & $270(73.6 \%)$ \\
\hline ECOG Performance status at study entry, n (\%) & $\mathrm{N}=350$ \\
\hline 0 & $140(40.0 \%)$ \\
\hline 3 & $158(45.1 \%)$ \\
\hline$\geq 2$ & $52(14.9 \%)$ \\
\hline $\begin{array}{l}\text { Time (months) between diagnostic of mCRC and initiation of the } \\
\text { first line chemotherapy }\end{array}$ & $\mathrm{N}=368$ \\
\hline Mean \pm SD & $1.11 \pm 0.70$ \\
\hline
\end{tabular}




\begin{tabular}{|c|c|}
\hline Median & 1 \\
\hline Q1-Q3 & $0.6-1.5$ \\
\hline First-line metastatic chemotherapy, n (\%) & $\mathrm{N}=364$ \\
\hline FOLFOX and/or XELOX & $186(51.1 \%)$ \\
\hline FOLFIRI and/or IRINOTECAN & $117(32.1 \%)$ \\
\hline 5 FU/LV IV and/or XELODA & $40(11.0 \%)$ \\
\hline FOLFIRINOX & $24(6.6 \%)$ \\
\hline Other chemotherapy & $3(0.8 \%)$ \\
\hline $\begin{array}{l}\text { Targeted therapy associated with first-line metastatic } \\
\text { chemotherapy, n (\%) }\end{array}$ & $\mathbf{N}=372$ \\
\hline At least one targeted therapy prescribed & $198(53.2 \%)$ \\
\hline Targeted therapy, n (\%) & $\mathrm{N}=197$ \\
\hline Cetuximab & $29(14.7 \%)$ \\
\hline Bevacizumab & $142(72.1 \%)$ \\
\hline Panitumumab & $23(11.7 \%)$ \\
\hline Aflibercept & $3(1.5 \%)$ \\
\hline
\end{tabular}

5-FU/LV IV: 5- 5-fluorouracil/leucovorin Intravenous; CRC: colorectal cancer; ECOG:

Eastern Cooperative Oncology Group; FOLFOX: 5-fluorouracil, levofolinate, oxaliplatin;

FOLFIRI: 5-fluorouracil, levofolinate, irinotecan; FOLFIRINOX: 5-fluorouracil, levofolinate, irinotecan, oxaliplatin; mCRC: metastatic colorectal cancer; N: number of patients with available data; SD: Standard Deviation; XELODA: capecitabine; XELOX: capecitabine, oxaliplatin 
Table 2: Characteristics of the RAS/KRAS mutation testing requests

\begin{tabular}{|c|c|}
\hline & $\begin{array}{c}\text { Total } \\
(\mathrm{N}=375)\end{array}$ \\
\hline RAS/KRAS mutation testing, n (\%) & $\mathbf{N}=375$ \\
\hline No mutation testing requested & $37(9.9 \%)$ \\
\hline At least one mutation test request & $338(90.1 \%)$ \\
\hline$R A S^{a}$ & $292(86.4 \%)$ \\
\hline$K R A S^{\mathrm{b}}$ & $31(\overline{9.2 \%)}$ \\
\hline Genotyping mCRC $^{\mathrm{c}}$ & $9(2.7 \%)$ \\
\hline Missing data & $6(1.8 \%)$ \\
\hline $\begin{array}{l}\text { Time between diagnosis of } \mathrm{mCRC} \text { and } R A S / K R A S \text { mutation testing } \\
\text { request, } \mathrm{n}(\%)\end{array}$ & $\mathbf{N}=331$ \\
\hline$>1$ month prior to diagnosis of metastases & $16(4.8 \%)$ \\
\hline$\leq 1$ month before and $\leq 1$ month after diagnosis of metastases & $242(73.1 \%)$ \\
\hline$>1$ month after diagnosis of metastases & $73(22.1 \%)$ \\
\hline $\begin{array}{l}\text { Time between } R A S / K R A S \text { mutation testing request and initiation of } \\
\text { first-line metastatic therapy, } n(\%)\end{array}$ & $\mathrm{N}=328$ \\
\hline Before the introduction of the first-line therapy & $280(85.4 \%)$ \\
\hline After the introduction of the first-line therapy & $48(14.6 \%)$ \\
\hline
\end{tabular}

${ }^{\mathrm{a}} \mathrm{RAS}=\overline{\mathrm{RAS}}$ or $K R A S+N R A S$ or $K R A S+N R A S+B R A F$

${ }^{b} K R A S=K R A S$ or $K R A S+B R A F$ or $K R A S+B R A F+$ microsatellite instability (MSI) phenotype

${ }^{\mathrm{c}}$ Genotyping mCRC=BRAF+MSI phenotype or MSI phenotype or Genotyping or CRC

biomarker 
Table 3: Duration in days of the time between test request and receipt of the genotyping report for $R A S / K R A S$ mutation testing

\begin{tabular}{|l|c|c|c|}
\hline & $\begin{array}{c}\text { Duration in days from } \\
\text { test request to } \\
\text { dispatch of tumour } \\
\text { material to platform } \\
\mathbf{( N = 2 3 7 )}\end{array}$ & $\begin{array}{r}\text { Duration in days from } \\
\text { dispatch of tumour } \\
\text { material to platform to } \\
\text { receipt of the } \\
\text { genotyping report }\end{array}$ & $\begin{array}{c}\text { Duration in days from } \\
\text { test request to receipt } \\
\text { of the genotyping } \\
\text { report }\end{array}$ \\
\hline Mean \pm SD & $7.7 \pm 11.3$ & $\mathbf{( N = 2 4 4 )}$ & $\mathbf{( N = 2 8 0 )}$ \\
\hline Median & 4.0 & $19.5 \pm 15.8$ & $24.6 \pm 17.2$ \\
\hline Q1-Q3 & $0.0-9.0$ & 15 & 20 \\
\hline Min; Max & $0.0 ; 65.0$ & $10.0-23.0$ & $14.0-29.0$ \\
\hline
\end{tabular}

Population: all patients, whatever the wording of the request, for whom there was a result for both KRAS and NRAS plus requests for RAS tests, for which there was at least one result for KRAS gene $(\mathrm{N}=304)$ 